\title{
Auditoria operacional no Tribunal de Contas do Estado do Ceará: um estudo no período de 2008 a 2017
}

\author{
Operational audit at the Court of Accounts of Ceará \\ between 2008 and 2017
}

\author{
Tatyanne Cavalcante Pimenta Gomes ${ }^{1}$ \\ Alessandra Carvalho de Vasconcelos ${ }^{2}$
}

\section{RESUMO}

Este estudo objetiva analisar a abordagem das auditorias de natureza operacionais (Anop) realizadas pelo Tribunal de Contas do Estado do Ceará (TCE/CE) quanto aos métodos e técnicas adotados e à utilização dos princípios da eficiência, economicidade, eficácia e efetividade. Os relatórios das Anop realizadas pelo TCE/CE entre 2008 (ano do primeiro trabalho desenvolvido pelo órgão) e 2017, foram analisados por meio de análise de conteúdo no intuito de classificar as questões e achados de auditoria dentre os sobreditos princípios. Ademais, também foi procedida a catalogação dos métodos de coleta e técnicas de auditoria empregados. Os resultados indicam que existe uma predominância na utilização do princípio da eficiência na composição das Anop do TCE/CE, em detrimento do princípio da economicidade, que é raramente utilizado. Ademais, os métodos de coleta mais empregados nas Anop são o exame documental, as entrevistas e os questionários, as técnicas de auditoria mais utilizadas são as análises stakeholder e SWOT.

\footnotetext{
1 Bacharel em Ciências Contábeis pela Universidade Estadual do Ceará (2012). Mestre em Administração e Controladoria pela Universidade Federal do Ceará (2018). Especialista em Fronteiras do Conhecimento em Auditoria Governamental: Desafios para o século XXI e em Direito Público, com ênfase em Direito Tributário. Atualmente é Analista de Controle Externo, especialidade Auditoria Governamental, no Tribunal de Contas do Estado do Ceará (TCE/CE). E-mail: tatycavpg@gmail.com.

2 Graduada em Ciências Econômicas (1995) e em Ciências Contábeis (2002) pela Universidade de Fortaleza, mestrado em Ciências Contábeis pela Fundação Universidade Regional de Blumenau (2006) e doutorado em Engenharia de Produção pela Universidade Federal de Santa Catarina (2009). Pesquisadora visitante na Pesquisadora visitante na Wageningen University \& Research (WUR) at Wageningen School of Social Sciences (WASS), Wageningen-Netherlands. Professora Associada da Universidade Federal do Ceará no curso de Graduação em Ciências Contábeis e no Programa de Pós-Graduação em Administração e Controladoria. Tem experiência na área de Contabilidade e Controladoria, atuando em pesquisas e produção científica com ênfase nos seguintes temas: controladoria, contabilidade financeira, governança corporativa, inovação, responsabilidade corporativa, sustentabilidade e internacionalização. E-mail: alevasconcelos.ufc@gmail.com
} 
Palavras-Chave: Auditoria Operacional. Princípios de desempenho. Métodos de auditoria. Tribunal de contas. TCE/CE.

\section{ABSTRACT}

This study analyzes the approach of operational audits (Anop) performed by the TCE/CE regarding the methods and techniques adopted and the use of the principles of efficiency, economy and effectiveness. The Anop reports made by the TCE/CE from 2008 (year of the first work developed by the institution) up until 2017 were verified with content analysis. The results indicate that there is a predominance in the use of the principle of efficiency in the composition of Anop, to the detriment of the principle of economy, which is rarely used. In addition, the commonly used collection methods in the Anop are documentary examination, interviews and questionnaires, and the most widely used auditing techniques are stakeholder and SWOT analysis.

Keywords: Operational audit. Principles of performance. Audit methods. Audit Office. TCE/CE.

Recebido: 15-12-2019

Aprovado: 17-02-2020

\section{INTRODUÇÃO}

A partir da percepção pelos Tribunais de Contas da necessidade de contribuir de forma mais relevante para o aprimoramento da gestão pública, em detrimento da cultura sancionatória, até então predominante, as cortes de contas aproximam-se da sociedade. Por conseguinte, os órgãos de controle assumem uma grande responsabilidade de intervir nas políticas públicas de maneira muito mais efetiva, utilizando-se da auditoria de natureza operacional para o alcance desse objetivo.

Segundo a Organização Internacional de Entidades Fiscalizadoras Superiores (INTOSAI, 2016), a auditoria operacional é um exame independente da economicidade, eficiência e efetividade dos desempenhos governamentais, programas ou organizações, com o intuito de verificar se é possível implementar 
ações de aperfeiçoamento. Ou seja, esse tipo de auditoria fornece informação para melhorar o desempenho e as operações de um determinado programa, objetivando facilitar a tomada de decisão das partes.

Dessa forma, a auditoria operacional caracteriza-se por ser uma auditoria analítica, destinada a realizar o controle da legitimidade e legalidade dos atos administrativos praticados, assim como favorecer a otimização dos recursos e a consistência e eficácia das ações governamentais. Outrossim, ao buscar, junto à população, as causas das situações que são reveladas pelas informações contábeis, fortalece a exteriorização do papel da auditoria governamental, tendo em vista a aproximação da sociedade civil.

Ademais, o uso da auditoria operacional está difundido em diversos Tribunais de Contas do Brasil, sendo que o primeiro trabalho desenvolvido pelo TCE/ CE nesse âmbito remonta ao ano de 2008. Dessa forma, essa Corte de Contas possui até a presente data 12 anos de experiência na área, além de boas avaliações no Marco de Medição de Desempenho dos Tribunais de Contas (MMD-TC), principal instrumento do Projeto Qualidade e Agilidade dos Tribunais de Contas (QATC) da Associação dos Membros dos Tribunais de Contas do Brasil (Atricon).

Tendo em vista a situação exposta, destaca-se a seguinte questão de pesquisa: Qual a abordagem das auditorias operacionais realizadas pelo TCE/CE? Com o intuito de responder este questionamento, o objetivo geral deste estudo é analisar a abordagem das auditorias operacionais realizadas pelo TCE/CE, quanto aos métodos e técnicas adotados e à utilização dos princípios eficiência, economicidade, eficácia e efetividade.

Diante da complexidade da temática, o assunto tem se desenvolvido por diversos organismos nacionais e internacionais incorporando, inclusive, novos campos de atuação, abordagens e métodos de trabalhos. Posto isso, a relevância dessa pesquisa acadêmica consiste na contribuição para o desenvolvimento das discussões acerca desse tema na academia, bem como da própria instituição analisada, ao explanar sobre a abordagem adotada nas auditorias operacionais realizadas pelo TCE/CE, tendo em vista que essa unidade de análise é inédita em estudos empíricos voltados para as auditorias de natureza operacional (Anop). 


\title{
2 REFERENCIAL TEÓRICO
}

\author{
2.1 Auditoria de Natureza Operacional (Anop) exercida pelos Tribunais \\ de Contas
}

A auditoria governamental no Setor Público é a atividade por meio da qual se confronta uma condição - o que é - com um determinado critério - o que deve ser - e é consubstanciada na emissão de um relatório imparcial e direto, onde se encontram as constatações positivas e negativas geradas no decorrer da auditoria. Esse conjunto de ações coordenadas e integradas contribui com as fiscalizações contábil, financeira, orçamentária, operacional e patrimonial, e constitui o controle público, tendo inclusive previsão constitucional. A auditoria governamental, no Brasil, é realizada, precipuamente, pelos Tribunais de Contas (ARAÚJO, 2011).

Vale ressaltar que os modelos de auditoria governamental efetuados pelas Entidades Fiscalizadoras Superiores (EFS), dividem-se em dois principais modelos, com abordagem operacional ou compreendendo somente aspectos legais e contábeis.

Por outro lado, a institucionalização do controle operacional na legislação brasileira se deu por meio da Constituição Federal de 1988 quando, por força do caput do artigo 70, foi atribuído ao Poder Legislativo com auxílio do Tribunal de Contas da União a competência para fiscalizar as gestões contábil, financeira, orçamentária, operacional e patrimonial da União e das entidades da administração direta e indireta (BRASIL, 1988).

No intuito de enriquecer este estudo, é importante definir alguns conceitos selecionados de auditoria operacional.

Dessa forma, o TCE/CE assim define ANOP no art. $2^{\circ}$ da Resolução Administrativa $\mathrm{n}^{\mathrm{o}} 10 / 2015$, seu manual de auditoria operacional:

A Auditoria Operacional compreende a avaliação das políticas públicas e das atividades governamentais dos órgãos e entidades, pautada, além dos aspectos de legalidade, em critérios de economicidade, eficiência, eficácia, efetividade, equidade, sustentabilidade e transparência, com a finalidade de promover o aperfeiçoamento da gestão pública (TRIBUNAL DE CONTAS DO ESTADO DO CEARÁ, 2015, p. 1). 
Para o General Accountability Office (GAO), Escritório da Controladoria Geral dos Estados Unidos da América:

As auditorias operacionais implicam exame objetivo e sistemático da evidência para apresentar uma avaliação independente do desempenho e da gestão de um programa com base em critérios objetivos, assim como avaliações que proporcionem um enfoque prospectivo ou que sintetizem informações sobre as melhores práticas ou análises de temas transversais (GAO, 2005, p. 45).

Segundo Pollit et al. (2008), existe um significado consensual lato a respeito da auditoria de natureza operacional (Anop) que as preconiza como uma forma de auditoria fundamentada na eficiência e na efetividade da gestão pública, contudo reconhece que ainda há muitas controvérsias sobre o papel que desempenham na estrutura governamental vigente.

Em atendimento aos ditames da Carta Magna, o Tribunal de Contas da União (TCU) também define a Anop: "o exame independente e objetivo da economicidade, eficiência, eficácia e efetividade de organizações, programas e atividades governamentais, com a finalidade de promover o aperfeiçoamento da gestão pública” (TRIBUNAL DE CONTAS DA UNIÃO, 2010, p. 11).

Os princípios da economicidade, eficiência, eficácia e efetividade elencados pelo TCU no conceito acima explicitado, são também definidas no seu manual. Resumidamente, o TCU preconiza que a economicidade concerne o custo mínimo na realização de uma atividade, sem comprometer-se com os padrões de qualidade. Enquanto a eficiência refere-se ao menor esforço no processo de transformação de insumos, guardando a qualidade dos produtos. Já a eficácia diz respeito à habilidade de atingir os objetivos imediatos, fornecendo bens e serviços conforme aquilo que foi planejado. A efetividade busca investigar se houve alterações no público abordado pelas ações do programa em análise (TCU, 2010).

A auditoria operacional geralmente segue uma das três abordagens: uma abordagem orientada a sistemas, que examina o adequado funcionamento dos sistemas de gestão, por exemplo, sistemas de gestão financeira; uma abordagem orientada a resultados, que avalia se os objetivos de impactos ou de produtos foram atingidos como planejados ou se os programas e serviços estão funcionando como pretendido; e uma abordagem orientada a problemas, que examina, verifica e analisa as causas de problemas específicos ou de desvios em relação a critérios (INTOSAI, 2013). 
Como as novas demandas sociais estão a exigir um novo padrão de informações geradas pela auditoria governamental realizada pelos Tribunais de Contas, seus relatórios - item essencial para comunicar a adequação das prestações de contas dos gestores públicos (auditoria contábil) e a avaliação dos resultados das políticas públicas (auditoria operacional) - devem ser elaborados para facilitar a interpretação dos fenômenos de gestão do setor público por parte dos seus atores interessados (ARAÚJO, 2011).

\subsection{Estudos anteriores sobre auditoria operacional em Tribunais de Contas}

Cabe ressaltar que, diante da sua importância, o tema auditoria operacional tem sido nos últimos anos foco de algumas discussões na academia. Contudo, percebe-se, pela análise dos estudos levantados, que não existe trabalho com enfoque na Corte de Contas Cearense, foco desta investigação. Dessa forma, considera-se oportuno o aprofundamento das investigações nesse âmbito sobre o assunto em pauta.

Nessa toada, o Quadro 1 apresenta um sumário de estudos sobre o tema, sob diferentes perspectivas.

Quadro 1: Sumário de estudos nacionais sobre Auditoria Operacional

\begin{tabular}{|c|l|l|}
\hline Autoria & \multicolumn{1}{|c|}{ Objetivo geral } & \multicolumn{1}{c|}{ Principais resultados } \\
\hline \multirow{4}{*}{$\begin{array}{c}\text { Albuquerque } \\
(2006)\end{array}$} & $\begin{array}{l}\text { Analisar se as auditorias operacionais } \\
\text { do TCU vêm cumprindo o seu duplo } \\
\text { papel de contribuir para a melhoria do } \\
\text { desempenho da ação de governo e de } \\
\text { garantir informações acerca do desem- } \\
\text { penho dos programas e organizações } \\
\text { governamentais. }\end{array}$ & $\begin{array}{l}\text { Os resultados revelaram que ainda não } \\
\text { foram introduzidos na Administração } \\
\text { Pública federal brasileira os meios e fer- } \\
\text { ramentas necessários para a viabilidade } \\
\text { do modelo de gerenciamento com base } \\
\text { em desempenho, como indicadores e } \\
\text { sistemas de gestão por objetivos e me- } \\
\text { tas. }\end{array}$ \\
\hline \multirow{3}{*}{$\begin{array}{l}\text { Oliveira } \\
(2008)\end{array}$} & $\begin{array}{l}\text { Investigar o estágio em que se encon- } \\
\text { tra a auditoria operacional no Tribunal } \\
\text { de Contas do Estado do Rio de Janeiro } \\
\text { (TCE/RJ), quais as modalidades já fo- } \\
\text { ram realizadas, os benefícios gerados } \\
\text { para a melhoria da gestão do gasto pú- } \\
\text { blico e os estágios que faltam para ser } \\
\text { plenamente implementada. }\end{array}$ & $\begin{array}{l}\text { Constatou-se que, apesar da cultura de } \\
\text { auditoria operacional ainda estar em } \\
\text { estágio embrionário, as mais recentes } \\
\text { ações administrativas, à época, abriram } \\
\text { excelentes perspectivas para superar o } \\
\text { desafio de sua consolidação no TCE/RJ. }\end{array}$ \\
\hline
\end{tabular}


Quadro 1: Sumário de estudos nacionais sobre Auditoria Operacional (continuação)

\begin{tabular}{|c|c|c|}
\hline Autoria & Objetivo geral & Principais resultados \\
\hline $\begin{array}{l}\text { Hedler e } \\
\text { Torres } \\
(2009)\end{array}$ & $\begin{array}{l}\text { Propor um modelo de meta avaliação } \\
\text { e aplicá-lo à Anop do TCU, avaliando } \\
\text { seus critérios, padrões, validade e con- } \\
\text { fiabilidade dos procedimentos e resul- } \\
\text { tados das Anop. }\end{array}$ & $\begin{array}{l}\text { Os resultados demonstram forças das } \\
\text { Anop, como avaliação do contexto e } \\
\text { checagem de características dos pro- } \\
\text { gramas e fraquezas relacionadas prin- } \\
\text { cipalmente à aplicação dos métodos e } \\
\text { técnicas da auditoria. }\end{array}$ \\
\hline $\begin{array}{l}\text { Graciliano } \\
\text { et al. }(2010)\end{array}$ & $\begin{array}{l}\text { Evidenciar como as Anop do TCU têm } \\
\text { contribuído no processo de accounta- } \\
\text { bility das entidades auditadas, utili- } \\
\text { zando o levantamento de sugestões e } \\
\text { críticas do TCU nas Anop. }\end{array}$ & $\begin{array}{l}\text { Os resultados indicam que o controle } \\
\text { externo da administração pública pode } \\
\text { ultrapassar os meandros da conformida- } \\
\text { de de procedimentos, contribuindo para } \\
\text { a melhoria de desempenho nos órgãos } \\
\text { auditados, quando se utiliza de audito- } \\
\text { rias operacionais. }\end{array}$ \\
\hline $\begin{array}{l}\text { Ribeiro Filho } \\
\text { et al. (2010) }\end{array}$ & $\begin{array}{l}\text { Verificar a possibilidade de identifi- } \\
\text { car fragilidades que comprometam a } \\
\text { eficácia das recomendações emitidas } \\
\text { pelas Anop realizadas pelo Tribunal } \\
\text { de Contas do Estado de Pernambuco } \\
\text { (TCE/PE), a partir do conceito de in- } \\
\text { teligência competitiva e com vistas a } \\
\text { subsidiar uma atuação preventiva e/ou } \\
\text { contingencial. }\end{array}$ & $\begin{array}{l}\text { Concluiu-se, com base na inteligência } \\
\text { competitiva, que há fragilidades que po- } \\
\text { dem comprometer a eficácia da imple- } \\
\text { mentação das recomendações emitidas } \\
\text { pela Anop, que uma vez identificadas } \\
\text { permitirão o estabelecimento de uma } \\
\text { estratégia preventiva e uma estratégia } \\
\text { contingencial, para fazer face aos fato- } \\
\text { res de risco, caso se concretizem. }\end{array}$ \\
\hline $\begin{array}{l}\text { Naves } \\
(2012)\end{array}$ & $\begin{array}{l}\text { Analisar o processo de instalação das } \\
\text { Anop nos Tribunais de Contas do Bra- } \\
\text { sil e, mais detidamente, no Tribunal } \\
\text { de Contas do Estado de Minas Gerais } \\
\text { (TCE/MG), aproximando essa recente } \\
\text { modalidade de fiscalização à visão ins- } \\
\text { titucionalista da accountability. }\end{array}$ & $\begin{array}{l}\text { Os resultados sugerem que as Anop não } \\
\text { estão institucionalizadas no ambiente } \\
\text { dos Tribunais de Contas subnacionais, } \\
\text { sendo executadas, com algumas exce- } \\
\text { ções, de forma rarefeita. }\end{array}$ \\
\hline $\begin{array}{l}\text { França } \\
(2012)\end{array}$ & $\begin{array}{l}\text { Verificar como os Tribunais de Contas } \\
\text { brasileiros estão lidando com a tarefa } \\
\text { de fiscalizar as questões relativas à } \\
\text { Anop. }\end{array}$ & $\begin{array}{l}\text { Constatou-se que, da forma com que as } \\
\text { Anop estão sendo realizadas no Brasil, } \\
\text { ainda há defasagem para que se possa } \\
\text { afirmar que os Tribunais estão lidando } \\
\text { com a tarefa de fiscalizar; devido à, } \\
\text { principalmente, falta de uma determi- } \\
\text { nação para imputar nominalmente os } \\
\text { responsáveis pela condução das reco- } \\
\text { mendações expedidas pelos Tribunais } \\
\text { de Contas, quando da publicação do } \\
\text { acórdão que se origina dos trabalhos de } \\
\text { auditoria. }\end{array}$ \\
\hline
\end{tabular}

Rev. Controle, Fortaleza, v. 18, n.1, p. 151-169, jan./jun. 2020. 
Quadro 1: Sumário de estudos nacionais sobre Auditoria Operacional (continuação)

\begin{tabular}{|c|c|c|}
\hline Autoria & Objetivo geral & Principais resultados \\
\hline $\begin{array}{l}\text { Barros et al. } \\
\quad(2015)\end{array}$ & $\begin{array}{l}\text { Analisar as avaliações de programas } \\
\text { realizadas pelo TCU, única Entidade } \\
\text { de Fiscalização Superior (EFS) no Bra- } \\
\text { sil, no período de } 2000-2012 \text {, revelan- } \\
\text { do os critérios no manuseio dos dados, } \\
\text { bem como os padrões utilizados pelo } \\
\text { órgão de controle externo. }\end{array}$ & $\begin{array}{l}\text { Concluiu-se que as avaliações de pro- } \\
\text { gramas realizadas pelo TCU se conver- } \\
\text { teram em subsídios para o aperfeiçoa- } \\
\text { mento dos rumos da gestão pública na } \\
\text { área da saúde, uma vez que delas resul- } \\
\text { taram } 305 \text { recomendações. }\end{array}$ \\
\hline $\begin{array}{l}\text { Silva } \\
(2015)\end{array}$ & $\begin{array}{l}\text { Investigar o processo de institucionali- } \\
\text { zação da Anop no TCU. }\end{array}$ & $\begin{array}{l}\text { Concluiu-se que o processo de insti- } \\
\text { tucionalização da Anop no TCU teve } \\
\text { início com ações isoladas baseadas em } \\
\text { interesses institucionais de homogenei- } \\
\text { zação de procedimentos, mas a sua acei- } \\
\text { tação reside na mudança de paradigma } \\
\text { da sociedade, que demanda maior trans- } \\
\text { parência e efetividade das ações gover- } \\
\text { namentais. }\end{array}$ \\
\hline $\begin{array}{l}\text { Melo e Paiva } \\
\qquad(2017)\end{array}$ & $\begin{array}{l}\text { Analisar a percepção dos auditores do } \\
\text { Tribunal de Contas do Estado da Paraí- } \\
\text { ba (TCE/PB) sobre o grau de importân- } \\
\text { cia e a possibilidade de materialização } \\
\text { dos benefícios potenciais da ANOP em } \\
\text { prol da administração pública. }\end{array}$ & $\begin{array}{l}\text { Os resultados revelaram que na per- } \\
\text { cepção dos auditores do TCE/PB, dos } \\
15 \text { principais benefícios potenciais } \\
\text { apontados pela doutrina, } 10 \text { deles têm } \\
\text { grandes possibilidades de materializa- } \\
\text { ção, permitindo a conclusão de que os } \\
\text { benefícios da ANOP se mostram com } \\
\text { potencial de promover a melhoria da } \\
\text { administração pública. }\end{array}$ \\
\hline
\end{tabular}

Fonte: Elaborada pelas autoras (2019).

Por meio da análise dos estudos apresentados no Quadro 1, pode-se perceber uma tendência nas pesquisas de relacionar a Anop e o aprimoramento da gestão pública. Estudos nesse diapasão foram realizados por Albuquerque (2006), Graciliano et al. (2010), França (2012) e Melo e Paiva (2017).

Por outro lado, Oliveira (2008), Naves (2012) e Silva (2015) buscaram avaliar os processos de institucionalização das Anop em Tribunais de Contas do Brasil. Ademais, Hedler e Torres (2009) e Ribeiro Filho et al. (2010) realizaram pesquisas mais pontuais que buscaram correlacionar a Anop com os construtos da meta avaliação e inteligência competitiva, respectivamente. Por fim, Barros et al. (2015) buscaram identificar os critérios e padrões utilizados nas Anop realizadas pelo TCU. 
Vale ressaltar que o principal diferencial desta pesquisa é investigar o perfil das Anop quanto aos métodos e técnicas adotados e à utilização dos princípios de eficiência, economicidade, eficácia e efetividade no âmbito do TCE/CE, unidade de análise inédita em estudos sobre esse tema.

\section{METODOLOGIA}

A pesquisa executada, de acordo com Gil (2009), pode ser classificada como descritiva, com base nos objetivos, e, quanto aos procedimentos técnicos utilizados, como pesquisa documental. Justifica-se a escolha do TCE/CE como unidade de análise pelo fato de que desde 2008 a auditoria operacional adotada é utilizada por esse Tribunal e em função da acessibilidade dos dados necessários para a consecução do objetivo proposto no estudo. Além disso, até o presente momento não foram identificadas pesquisas acadêmicas voltadas para as Anop nessa Corte de Contas.

Para a operacionalização da pesquisa, foram analisados os relatórios das auditorias operacionais realizadas pelo TCE/CE e já publicadas, compreendendo o período de 2008 a 2017, observando-se, essencialmente, na análise da abordagem das auditorias, os princípios de desempenho e os métodos de auditoria adotados nesses trabalhos. Justifica-se a seleção do período de análise à ocorrência da primeira Anop realizada pelo TCE/CE remontar ao ano de 2008 e à existência de relatórios publicados no website do Tribunal no dia 1 ago. 2018, o que favoreceu o acesso aos dados. Cabe informar que os dados coletados, extraídos dos relatórios de auditoria, foram discutidos à luz do contexto da Nova Gestão Pública (NGP) e do estágio de desenvolvimento da auditoria operacional nos demais Tribunais de Contas.

Foi realizada análise quantitativa por meio da técnica de análise de conteúdo dos relatórios de auditoria operacional quanto à verificação da abordagem relacionada aos princípios de desempenho e aos métodos de auditoria adotados nesses trabalhos. À luz do Manual de auditoria operacional do TCU (TRIBUNAL DE CONTAS DA UNIÃO, 2010), os princípios de auditoria operacional são quatro: a economicidade, a eficiência, a eficácia e a efetividade. Os princípios utilizados nas Anop realizadas pelo TCE/CE não são explicitados nos relatórios produzidos, sendo necessário identificá-los ao longo dos textos, onde aparecem de modo implícito, e, em seguida, classificá-los dentro de um dos quatro princípios citados. 
Assim, atribuiu-se a cada questão e a cada achado de auditoria nos relatórios apenas um dos quatro princípios de desempenho. Naqueles casos em que a questão ou o achado comportariam mais de um princípio de desempenho, optou-se por aquele considerado preponderante à situação. Por outro lado, uma auditoria pode conter mais de um método de coleta e técnica de auditoria, bem como enquadrar-se em mais de um princípio por conter questões que abordem diferentes princípios.

Segundo Bardin (2011), a análise de conteúdo envolve um conjunto de técnicas de análise das comunicações visando a obter, por procedimentos sistemáticos de descrição do conteúdo das mensagens, indicadores que permitam a inferência de conhecimentos relativos às condições de produção destas mensagens, com ênfase em categorias selecionados a priori ou a posteriori.

Este estudo trabalhou com as seguintes categorias e subcategorias selecionadas a priori, com base nos estudos de Albuquerque (2007): (1) categorias: economicidade, eficiência, eficácia e efetividade; e (2) subcategorias: custos, processos, metas e impactos, respectivamente. Dessa forma, a classificação das questões e achados de auditoria nas categorias elencadas teve por base a identificação da temática preponderante dentre as sobreditas subcategorias.

De 2008 a 2017, o TCE/CE realizou 12 auditorias operacionais, as quais relacionam-se os seus respectivos objetos, ano a ano:

- 2008: Pró-Letramento - Formação continuada de professores do Ensino Fundamental;

- 2009: Estratégia Saúde da Família (ESF);

- 2010: pequenos sistemas simplificados de abastecimento d'água em comunidades rurais;

- 2011: criação e gestão de unidades de conservação de proteção integral;

- 2012: ronda do quarteirão;

- 2013: Ensino Médio;

- 2014: nível de atenção básica;

- 2015: transporte escolar e gestão de recursos hídricos;

- 2016: regimes próprios de previdência social dos servidores públicos do estado do Ceará;

- 2017: Diagnóstico Avaliação de Políticas Públicas - atividades de monitoramento e avaliação de políticas públicas para o acompanhamento do PPA 2016/2019-e Diagnóstico PNE - exame de ações governamentais do estado do Ceará relacionadas 
com a Meta 3 do Plano Nacional de Educação (PNE 2014-2024), que prevê a universalização do atendimento escolar aos jovens de 15 a 17 anos.

Buscou-se identificar a abordagem adotada em cada uma das 12 Anop mencionadas, quanto aos métodos e técnicas empregados e à utilização dos princípios eficiência, economicidade, eficácia e efetividade. Cabe informar que a análise foi realizada em dois momentos distintos do processo auditorial: (1) na formulação das questões de auditoria, feita na fase de planejamento dos trabalhos; e (2) no desenvolvimento dos achados de auditoria, bem como também foi examinada a frequência dos métodos de coleta de dados e técnicas de auditoria adotados pelo TCE/CE.

Ademais, para melhor compreensão da análise de conteúdo realizada, o Quadro 2 apresenta exemplos de questões e achados de auditoria com a identificação das categorias (princípios) atribuídos a eles.

Quadro 2: Exemplificação da classificação das questões e dos achados de auditoria

\begin{tabular}{|c|l|c|}
\hline \multicolumn{2}{|c|}{ Questões e achados de auditoria } & Categorias \\
\hline $\begin{array}{c}\text { Questão da auditoria: } \\
\text { Ronda do Quarteirão } \\
\text { (RONDA) }\end{array}$ & $\begin{array}{l}\text { As ações formativas (inicial e continuada) qualificam } \\
\text { os policiais do RONDA a desempenhar as atividades } \\
\text { de policiamento comunitário? }\end{array}$ & Eficácia \\
\hline $\begin{array}{c}\text { Achado da auditoria: } \\
\text { Nível de Atenção } \\
\text { Básica }\end{array}$ & $\begin{array}{l}\text { Deficiência na estrutura de Tecnologia da Informação } \\
\text { (TI): rede, equipamentos de informática, softwares, } \\
\text { manutenção e suporte técnico. }\end{array}$ & Eficiência \\
\hline $\begin{array}{c}\text { Achado da auditoria: } \\
\text { Regimes Próprios de } \\
\begin{array}{c}\text { Previdência Social dos } \\
\text { Servidores Públicos do } \\
\text { Estado do Ceará }\end{array}\end{array}$ & $\begin{array}{l}\text { Premissa da taxa de juros utilizada na avaliação atu- } \\
\text { arial, referente a carteira de investimentos, acima da } \\
\text { realidade do mercado. }\end{array}$ & Economicidade \\
\hline $\begin{array}{c}\text { Achado da auditoria: } \\
\text { Transporte escolar }\end{array}$ & $\begin{array}{l}\text { A utilização do transporte escolar não está garantindo } \\
\text { a frequência dos alunos à escola. }\end{array}$ & Efetividade \\
\hline
\end{tabular}

Fonte: Elaborado pelas autoras (2019).

Destaca-se que, apesar do rigor metodológico adotado na consecução da análise dos documentos, a subjetividade na interpretação do conteúdo dos relatórios é uma limitação deste estudo, inerente à técnica de análise de conteúdo. 


\section{RESULTADOS DA PESQUISA}

Este estudo buscou analisar a abordagem das auditorias operacionais realizadas pelo TCE/CE, de 2008 a 2017, por meio da análise de conteúdo dos 12 relatórios obtidos com as auditorias, obtendo-se os resultados apresentados nos gráficos dispostos a seguir.

Inicialmente, o Gráfico 1 demonstra que a eficiência foi o princípio de desempenho mais frequente, com 32 questões, representando $60 \%$ das observações, enquanto o princípio eficácia foi o menos utilizado na elaboração das questões, com apenas três ocorrências, ou seja, $6 \%$ do rol de dados.

Dessa forma, constata-se que os resultados obtidos informam uma nítida tendência de questões de auditoria relacionadas ao princípio da eficiência, ao passo que efetividade e economicidade compuseram as demais questões, representando $25 \%$ e $9 \%$ das questões, respectivamente.

Essa conjuntura de predomínio do princípio eficiência nas questões de auditoria também foi encontrado por Albuquerque (2006). Contudo, em relação à frequência de utilização dos demais princípios, não se pode afirmar isso, tendo em vista que no estudo realizado pelo autor, a presença de questões relacionadas à eficácia alcançou o segundo maior número de ocorrências, sucedida pela efetividade e a economicidade.

Gráfico 1: Frequência dos princípios nas questões de auditoria

\section{Frequência dos Principios nas Questões de} Auditoria

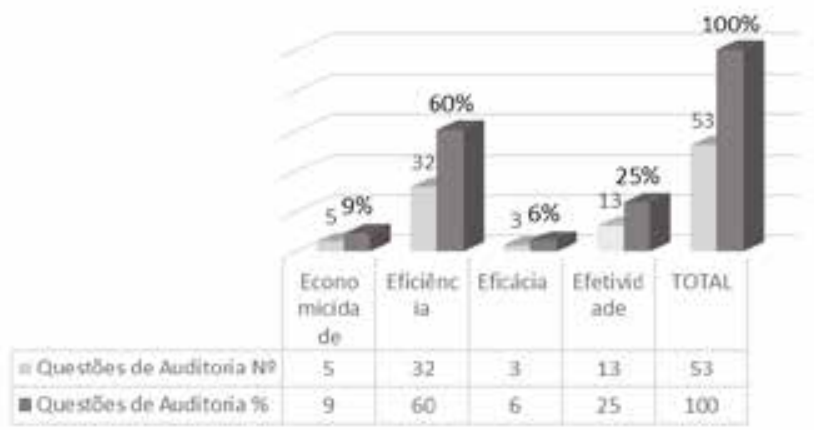

Fonte: Elaborado pelas autoras (2019). 
Após a classificação dos achados de auditoria conforme os princípios de desempenho adotados nesse estudo, apresenta-se no Gráfico 2 a distribuição das suas frequências.

Gráfico 2: Frequência dos princípios nos achados de auditoria

\section{Frequência dos Principios nos Achados de Auditoria}

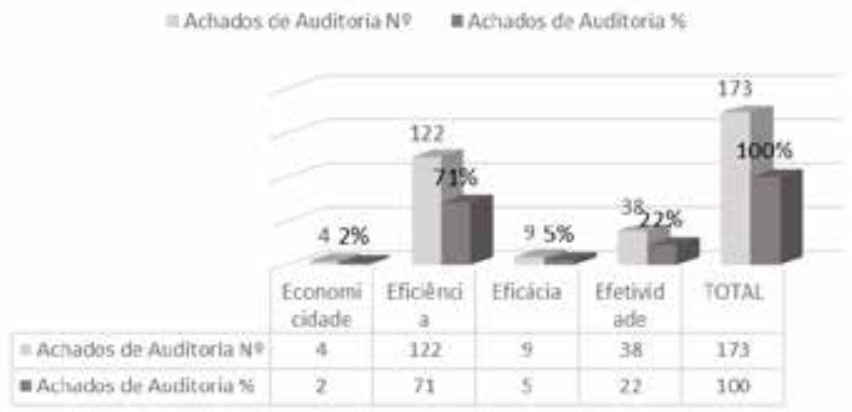

Fonte: Elaborado pelas autoras (2019).

Por meio da análise do Gráfico 2, constata-se que dos 173 achados de auditoria classificados, 122 deles referem-se à eficiência, representando $71 \%$ das observações. Esses achados, amplamente predominantes, se reportam, em sua grande maioria, aos sistemas e práticas gerenciais. Dessa forma, destaca-se que esse panorama se assemelha ao encontrado na análise da frequência dos princípios nas questões de auditoria, bem como converge e diverge dos mesmos pontos já relatados do estudo de Albuquerque (2006).

A maioria dos achados origina-se da inexistência ou escassez de dados e indicadores de desempenho, o que compromete o alcance da eficiência na execução dos programas e consequentemente prejudica as ações de supervisão, acompanhamento e monitoramento, acarretando em outros achados. Verifica-se também alguns achados que concernem às limitações na integração entre os níveis de governo e os agentes responsáveis pela realização dos programas, além de ausência de infraestrutura, recursos materiais e pessoal adequados.

Com referência aos procedimentos de coleta de dados, no Gráfico 3 pode-se observar que o método mais utilizado foi o exame documental, sendo elen- 
cado em praticamente todas as auditorias. Os métodos entrevista e questionário também obtiveram um número expressivo de ocorrência, constando em dez das doze auditorias analisadas. Por outro lado, a metodologia da observação direta, bem como o levantamento e análise de dados secundários foram apontados como utilizados em cinco e sete auditorias, respectivamente.

Vale ainda mencionar que o método do grupo focal não foi destacado em nenhuma das auditorias, sendo a sua utilização ignorada nos relatórios examinados. A despeito disso, importa destacar que pode ter sido utilizado mais de um método no desenvolvimento de cada auditoria.

Gráfico 3: Frequência dos métodos de coleta

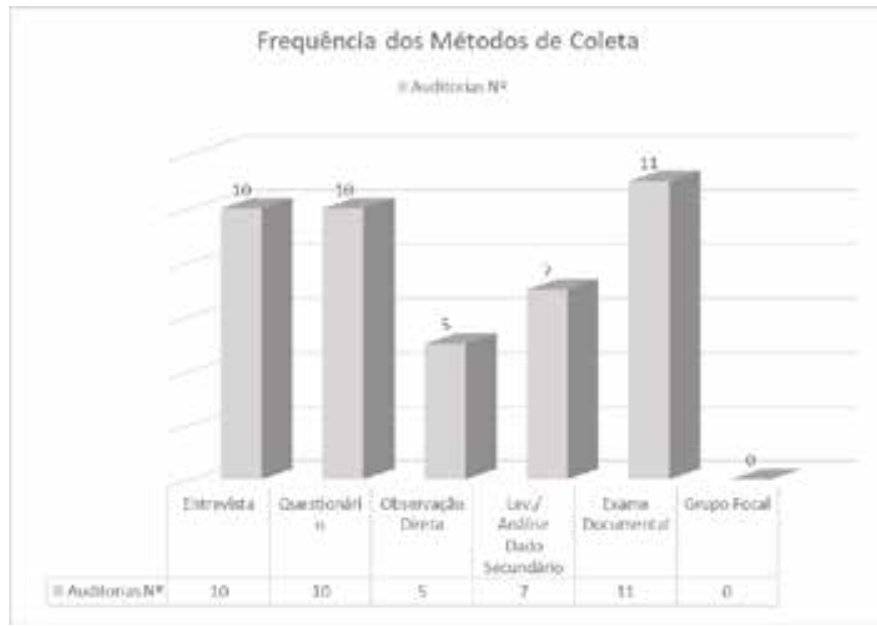

Fonte: Elaborado pelas autoras (2019).

Quanto às denominadas técnicas de auditoria, verifica-se no Gráfico 4 que o mapa de produtos foi a menos utilizada nas Anop do TCE/CE, em contraposição a aplicação na maioria das auditorias das análises stakeholder e SWOT.

Ademais, também foram empregadas as técnicas de verificação de risco e o mapa de processo em seis e quatro auditorias, respectivamente. Sob outra perspectiva, importa destacar que pode ter sido utilizada mais de uma técnica no desenvolvimento de cada auditoria. 
Gráfico 4: Frequência das técnicas de auditoria

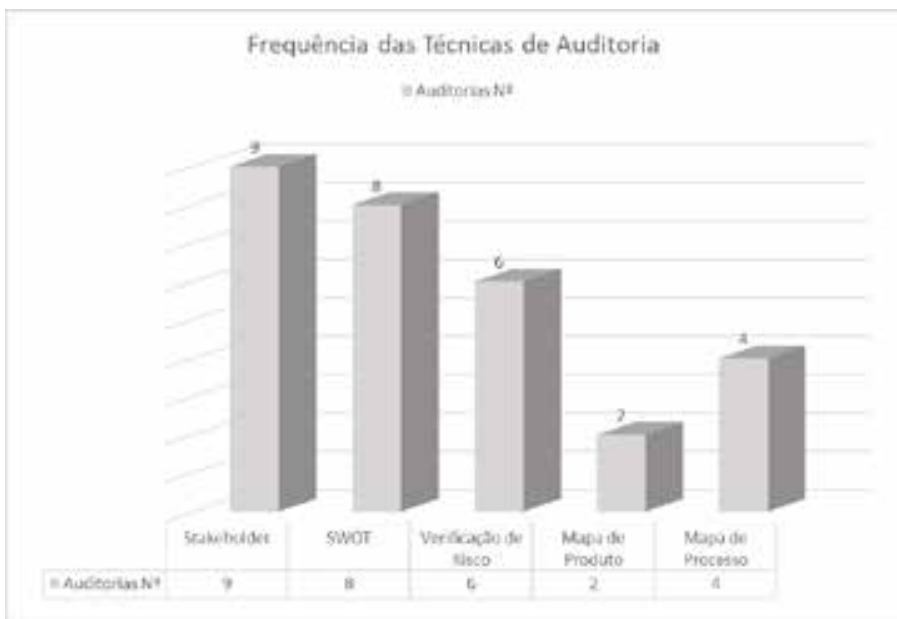

Fonte: Elaborado pelas autoras (2019).

Ao comparar os resultados obtidos, em relação aos métodos e técnicas de auditoria adotados pelo Manual de Auditoria Operacional do TCE/CE, com a pesquisa realizada por Barros et al. (2015), observa-se que esses autores elencaram 17 ferramentas de diagnóstico, entre métodos e técnicas, utilizadas pelo TCU, abrangendo 10 procedimentos diferentes dos identificados nesta pesquisa. Quais sejam: análise envoltória de dados (DEA), árvore de problemas, metodologia COSO, diagrama de Ishikawa, estudo de caso, mapa cognitivo, pesquisa postal, análise RECI, teste piloto e visitas de estudo.

Dessa forma, após apresentar a frequência dos princípios nas 12 Anop realizadas pelo TCE/CE no período de 2008 a 2017, nas suas questões e achados, bem como dos métodos e técnicas adotados, foi possível constatar que, predominantemente, a abordagem adotada pelo TCE/CE na realização das auditorias operacionais é orientada ao princípio da eficiência. 


\section{CONSIDERAÇÕES FINAIS}

Este estudo teve o objetivo de analisar a abordagem das auditorias operacionais realizadas pelo $\mathrm{TCE} / \mathrm{CE}$ quanto aos métodos e técnicas adotados e à utilização dos princípios eficiência, economicidade, eficácia e efetividade.

Foi empreendida a análise de conteúdo dos relatórios de auditoria operacional realizadas pelo TCE/CE do período de 2008 a 2017, por meio da qual foi constatada a predominância na utilização do princípio eficiência na composição das auditorias operacionais, em detrimento do princípio da economicidade, o qual é raramente utilizado. Quanto aos métodos de coleta, constatou-se que os mais utilizados são o exame documental, as entrevistas e os questionários. Por outro lado, em relação às técnicas de auditoria, verificou-se que as análises stakeholder e SWOT são mais frequentes.

Ante a investigação e, considerando o rol de dados e o lapso temporal analisado, é possível responder o problema de pesquisa, concluindo que a abordagem adotada pelo TCE/CE na execução das auditorias operacionais é orientada pelo princípio da eficiência, pois examina predominantemente o adequado funcionamento dos sistemas de gestão.

Ao confrontar os resultados desta pesquisa com os estudos empíricos anteriores, pôde-se observar que, em linhas gerais, os resultados encontrados estão alinhados aos achados de Albuquerque (2006), que teve como locus da pesquisa o Tribunal de Contas da União, o qual apresenta metodologia bem semelhante com a empregada pelo TCE/CE observada neste trabalho.

A contribuição desta pesquisa abrange o aprofundamento das discussões sobre o tema no ambiente do controle externo brasileiro, tendo em vista os poucos trabalhos empíricos publicados abordando a auditoria operacional nos Tribunais de Contas desse país. Do ponto de vista acadêmico, acredita-se que a pesquisa trouxe evidências empíricas que podem servir de ponto de partida para outras investigações, ou para o aprofundamento do entendimento do tema em foco.

Além disso, a pesquisa propiciou a identificação do direcionamento adotado pelo TCE/CE na execução das Anop, qual seja, a primazia pelo princípio da eficiência no concernente ao exame do funcionamento dos sistemas de gestão na administração pública cearense. Sob outra perspectiva, ao constatar que as técnicas de auditoria mais utilizadas na série temporal estudada são as análises stakeholder e SWOT pôde-se vislumbrar que, na seara de atuação desta Egrégia 
Corte de Contas, a auditoria de natureza operacional torna-se um instrumento de aproximação do controle externo da sociedade e de aprimoramento das políticas públicas por meio do reconhecimento das melhores práticas.

Como limitações deste estudo, destaca-se que existem outros princípios de desempenho que podem ser observados, como equidade, sustentabilidade e transparência. Limitando-se esta investigação apenas aos quatro principais elencados na literatura, que são economicidade, eficiência, eficácia e efetividade e, apesar do rigor metodológico aplicado na realização do estudo, vale citar também um certo grau de subjetividade inerente à análise de conteúdo - uma vez que a percepção do pesquisador pode influenciar na atribuição das classificações.

Por fim, as sugestões para futuras pesquisas passam por uma análise longitudinal, que relacione todos os princípios, bem como outras abordagens que se relacionam a esse tema podem ser utilizadas, como a auditoria integrada e a aplicação dos índices de efetividade estaduais e municipais propostos pelo Instituto Rui Barbosa (IRB).

\section{REFERÊNCIAS}

ALBUQUERQUE, F. F. T. A auditoria operacional e seus desafios: um estudo a partir da experiência do Tribunal de Contas da União. 2006. 153 f. Dissertação (Mestrado Profissional em Administração) - Universidade Federal da Bahia, Salvador, 2006.

ARAÚJO, I. P. S. Auditoria operacional: o sonho em realidade. Revista do Tribunal de Contas do Estado da Paraíba, João Pessoa, ano V, n. 9, p. 67-89, 2011.

BARDIN, L. Análise de conteúdo. São Paulo: Edições 70, 2011.

BARROS, C. C. et al. Avaliações de programas públicos realizadas pelo TCU na área de saúde. Revista Catarinense da Ciência Contábil, Florianópolis, v. 14, n. 41 , p. $20-32,2015$.

BRASIL. [Constituição (1988)]. Constituiçãa da República Federativa do Brasil. Brasília, DF: Assembleia Legislativa do Brasil, 1988. Disponível em: http://bit.ly/2Tm1mXy. Acesso em: 27 nov. 2017. 
ESTADOS UNIDOS DA AMÉRICA. Escritório de Accountability Governamental. Normas de auditoria governamental. Salvador: Tribunal de Contas do Estado da Bahia, 2005.

FRANÇA, A. M. B. Do controle da legalidade às auditorias operacionais: os Tribunais de Contas e o controle financeiro da administração pública brasileira. 2012. 75 f. Dissertação (Mestrado Profissional em Gestão e Políticas Públicas) - Fundação Getúlio Vargas, São Paulo, 2012.

GIL, A. C. Métodos e técnicas de pesquisa social. São Paulo: Atlas. 2009.

GRACILIANO, E. A. et al. Accountability na administração pública federal: contribuição das auditorias operacionais do TCU. Pensar Contábil, Rio de Janeiro, v. 12, n. 47, p. 43-51, jan./mar. 2010.

HEDLER, H. C.; TORRES, C. V. Meta-avaliação de auditorias de natureza operacional do Tribunal de Contas da União. Revista de Administração Contemporânea, Maringá, v. 13, n. 3, p. 468-486, 2009.

MELO, G. J. P.; PAIVA, S. B. Benefícios potenciais da auditoria operacional para a administração pública: a percepção dos auditores do TCE/PB. RACE, Joaçaba, v. 16, n. 1, p. 353-380, 2017.

NAVES, L. E. P. Auditorias operacionais a cargo dos tribunais de contas brasileiros e accountability vertical e horizontal: análise do processo de institucionalização depois de 1988. 2012. 129f. Dissertação (Mestrado em Administração Pública) - Fundação João Pinheiro, Belo Horizonte, 2012.

OLIVEIRA, R. V. Auditoria operacional: uma nova ótica dos tribunais de contas auditarem a gestão pública, sob o prisma da eficiência, economicidade, eficácia e efetividade, e o desafio de sua consolidação no TCE/RJ. 2008. 123 f. Dissertação (Mestrado em Administração Pública) - Fundação Getúlio Vargas , Rio de Janeiro, 2008. 
ORGANIZAÇÃO INTERNACIONAL DE ENTIDADES FISCALIZADORAS SUPERIORES. ISSAI 300: princípios fundamentais de auditoria operacional. Tradução: Tribunal de Contas da União. Viena: Intosai, 2017. Disponível em: http://bit.ly/2V9sADd. Data de acesso: 17 fev. 2020.

ORGANIZAÇÃO INTERNACIONAL DE ENTIDADES FISCALIZADORAS SUPERIORES. ISSAI 3000: norma para auditoria operacional. Tradução: Tribunal de Contas da União. Viena: Intosai, 2016. Disponível em: http://bit. ly/2wwp8by. Acesso em: 17 fev. 2020.

POLLIT, C.; GIRRE, X.; SUMMA, H.; LONSDALE, J.; WAERNESS, M.; MUL, R. Desempenho ou legalidade? Auditoria operacional e de gestão pública em cinco países. Tradução Pedro Buck. Belo Horizonte: Fórum, 2008.

RIBEIRO FILHO, J. F. et al. Recomendações em auditoria operacional: uma prospecção de fragilidades, com base na inteligência competitiva. Revista de Administração da UFSM, Santa Maria, v. 3, n. 2, p. 191-204, maio/ago. 2010.

SILVA, H. R. Avaliação de políticas públicas: Um estudo sobre auditoria de desempenho no Tribunal de Contas da União brasileiro. 2015. 127 f. Dissertação (Mestrado em Desenvolvimento, Sociedade e Cooperação Internacional) - Universidade de Brasília, Brasília, DF, 2015.

TRIBUNAL DE CONTAS DA UNIÃO (Brasil). Manual de auditoria operacional. 3. ed. Brasília, DF: TCU, 2010.

TRIBUNAL DE CONTAS DO ESTADO DO CEARÁ. Resolução n ${ }^{\circ}$ 10/2015: Dispõe sobre a Auditoria Operacional realizada pelo Tribunal de Contas do Estado do Ceará. Diário Oficial do Tribunal de Contas do Estado do Ceará: Secretaria Geral: Resolução Administrativa, Fortaleza, ano 2, n. 226, p. 14-55, 16 dez. 2015. 